\title{
Estudo da viabilidade econômica para produção de agregado sinterizado de argila calcinada
}

\section{(Study of economic viability for production of sintered aggregate of calcined clay)}

\author{
A. C. L. da Silva, C. A. Frota \\ Grupo de Geotecnia, Faculdade de Tecnologia, Universidade Federal do Amazonas - UFAM \\ Av. General Rodrigo Octávio Jordão Ramos 3000, Manaus, AM 69077-000 \\ cleiton.acls@hotmail.com,cafrota@ufam.edu.br
}

\begin{abstract}
Resumo
Ante a carência de materiais pétreos na região amazônica (déficit prejudicial ao seu emprego, nas obras civis, como agregado graúdo), desenvolveu-se pesquisa científico-tecnológica voltada a materiais alternativos, por meio da qual se constatou a viabilidade técnica do Agregado Sinterizado de Argila Calcinada - ASAC, na composição de misturas asfálticas destinadas aos pavimentos rodoviários amazônicos. Por outro lado, levantamentos demonstraram abundância na Amazônia da matéria para a sua confecção, que permitirá sua obtenção em larga escala, mesmo em locais de difícil acesso, motivos pelos quais se mostra indispensável aferir os custos do seu processo produtivo. Estabeleceu-se metodologia de análise de custos de confecção de produtos de cerâmica vermelha, que pode ser utilizado para produção do ASAC. Em junho de 2012 o exame preliminar constatou para o ASAC preço 40\% superior ao do seixo (tradicional opção regional ao agregado pétreo), ao passo que, quanto ao agregado tradicional, detectou-se preço muito abaixo da média usual, com tendência de recuperação, de sorte que a produção do agregado sinterizado apresenta-se vantajosa, no médio e longo prazos. Com efeito, a análise mais detalhada, em que o processo produtivo foi adaptado à produção do agregado artificial, apontou fato promissor: o preço final com valor $24 \%$ acima do seixo rolado. No contexto da produção para a aplicação direta na obra civil, a situação se inverte, porquanto apenas os custos diretos de produção compõem o custo do ASAC, revelando-se $34,5 \%$ inferior ao preço do agregado aluvionar, este, ressalta-se, abaixo da sua média histórica. Computando-se custos adicionais de transporte para o seixo rolado, quando o local da obra é distante dos centros comerciais, a vantagem financeira do ASAC aumenta de forma expressiva, a ponto de alcançar preço $77 \%$ inferior ao do seixo rolado (por exemplo, para uma distância média de $400 \mathrm{~km}$ ). Palavras-chave: agregados sintéticos, produção, custos.
\end{abstract}

\begin{abstract}
Faced with a shortage of stone materials in the Amazon region (deficit detrimental to their employment in civil works such as coarse aggregate), developed scientific-technological research focused on alternative materials, through which verified the feasibility of Aggregate Sintered Calcined Clay - ASAC, to composition of asphalt mixtures for road pavements to Amazon. Moreover, surveys showed plenty of matter in the Amazon for its confection, which allow obtaining a large scale, even in hard to reach places, reasons is indispensable to assess the costs of its production process. It was established methodology for analyzing cost of making red ceramic products, which can be used to produce the ASAC. In June 2012, the preliminary examination found, for ASAC, price 40\% higher than the pebble (traditional regional option to aggregate stony), while, on the traditional aggregate, we detected a price far below the usual average, with recovery trend, so that the production of sintered aggregate proved to be advantageous in the medium and long term. Indeed, the further analysis, in which the production process was adapted for production of the artificial aggregate, appointed fact promising: the price final value $24 \%$ above the pebble. In the context of production for direct application in civil work, the situation is reversed, since only the direct production costs comprise the cost of ASAC, revealing $34.5 \%$ less than the price of alluvial aggregate, this, it is emphasized, below its historical average. Computing the additional transport costs to the pebble, when the construction site is far from the shopping centers, the financial advantage of the ASAC increases significantly, to the point of achieving price $77 \%$ lower than the pebble (e.g. for an average distance of $400 \mathrm{~km}$ ).
\end{abstract}

Keywords: synthetic aggregates, production, costs.

\section{INTRODUÇÃO}

Um dos mais importantes insumos para a construção civil é os agregados, termo genérico para areias, pedregulhos e rochas minerais em seu estado natural ou britadas [1]. No caso da pavimentação, a qualidade do revestimento asfáltico depende, sobremaneira, das características do agregado graúdo que, por sua vez, decorrem da rocha originária, destacando-se com melhores desempenhos os provenientes de rochas ígneas e metamórficas. No entanto, na região amazônica, tais materiais são escassos e, quando possível a sua obtenção, provém, em geral, de rochas 
sedimentares, razão pela qual se utiliza, tradicionalmente, o seixo rolado, extraído do leito de rios, e outros materiais de menor qualidade. Além de inferior sob o prisma técnico, sua exploração acarreta sérios impactos ambientais e implica altos custos, sobretudo em razão das grandes distâncias de transportes entre os locais de exploração e o mercado consumidor. $\mathrm{Na}$ busca por materiais alternativos, diversos estudos apontam pela viabilidade técnica do Agregado Sinterizado de Argila Calcinada (ASAC) [2-8], e comprovam a abundância de sua matéria-prima no estado do Amazonas, região compreendida desde a Província Petrolífera do Urucu, no Município de Coari até ao sul do município de Manaus, incluindo a porção leste do rio Solimões e sua confluência com o rio Negro [9], bem como no entorno da rodovia BR-319 [5]. Tratando-se da produção em larga escala do agregado sinterizado, com a finalidade de substituição parcial, ou até mesmo total, do seixo rolado, mostram-se imprescindíveis estudos acerca de sua viabilidade econômica, como maneira de incentivar investimentos, pelos setores público e privado, por se tratar de insumo básico para a melhoria da infra-estrutura de transportes, no que concerne, em particular, à pavimentação de rodovias e vias urbanas, a exemplo do caso ilustrativo de Manaus, cuja malha viária necessita de maior qualidade técnica, ante a ausência, mormente, de agregado graúdo no compósito asfáltico. Dessa forma, apresenta-se no trabalho em pauta uma análise da viabilidade econômica da produção do Agregado Sinterizado de Argila Calcinada tanto para fins comerciais quanto para consumo próprio.

\section{MATERIAIS E MÉTODOS}

A análise realizada consistiu em calcular o preço de mercado da produção industrial do Agregado Sinterizado de Argila Calcinada, a fim de compará-lo com os custos dos agregados graúdos usualmente comercializados na região. Os preços de mercado do seixo rolado, opção regional ao agregado pétreo, foram obtidos por meio do Sistema Nacional de Pesquisa de Custos e Índices da Construção Civil (SINAPI), gerenciado pela Caixa Econômica Federal [10], com apoio do Instituto Brasileiro de Geografia e Estatística (IBGE), responsável por pesquisas mensais de preços.

Como método de produção do ASAC, considerou-se a extrusão e corte da argila moldada, de maneira similar ao realizado pelas indústrias de cerâmica vermelha, também chamada de cerâmica estrutural, com ajustes na conformação final do produto, sendo esta de acordo com a boquilha da extrusora. Dessa forma, pode-se partir de uma estrutura e processo produtivo padrão utilizado pela citada indústria cerâmica, sem grandes distorções do processo produtivo.

\section{Análise preliminar}

Em termos gerais, independente das dimensões do produto final, os custos de produtos cerâmicos podem ser referenciados à massa total de argila processada. Sob essa premissa, realizou-se um levantamento inicial expedito a fim de se estabelecer um parâmetro comparativo. Nessa fase não se avaliou a estrutura, métodos, processos produtivos, eficiência ou qualquer custo direto. Comparou-se a massa equivalente de ASAC, que poderia ser produzida similar aos produtos tradicionais encontrados no mercado, no caso, com o tijolo cerâmico de oito furos. Há que se destacar que o custo de produção do ASAC tende a ser menor relativo ao tijolo, porquanto não requer cuidados inerentes ao manuseio, diminuindo as despesas com mão de obra, assim como não apresenta problemas com perdas de blocos cerâmicos. Dessa forma, foram coletados tijolos de oito furos após o processo de fabricação, com medidas aproximadas de $9 \mathrm{~cm}$ x $19 \mathrm{~cm}$ x $19 \mathrm{~cm}$, a fim de se determinar sua massa média e, por conseguinte, o preço por unidade de massa, a partir de sua correlação com o preço por tijolo, que também foi obtido junto ao SINAPI [10]. De posse do preço da argila calcinada por unidade de massa e da massa específica aparente do ASAC, obtém-se o preço volumétrico correspondente do agregado sinterizado. Para melhorar a precisão do cálculo analisaramse outras questões atinentes à produção do agregado alternativo, notadamente as concernentes à eficiência do processo produtivo, considerando-se a produção em larga escala. Visou-se baixar os custos e o preço final do produto, tornando-o mais competitivo. Ao mesmo tempo, avaliou-se um cenário de uso em locais distantes, como normalmente acontece quando da execução de obras rodoviárias, em que os custos relacionados ao transporte comercial do seixo rolado são expressivos, exemplo de Manaus. Assim, conferindo grande vantagem financeira à produção do ASAC em usinas locais, como já acontece tradicionalmente nesse tipo de obra com centrais de britagem, usinas de solos, asfalto etc. Após essa ponderação incluíram-se no estudo os custos unitários de produção, ocasião em que pode ser avaliada a eficiência do processo produtivo, bem como a análise a partir do cenário da execução de obras rodoviárias além do perímetro urbano.

Deve ser ressaltada a importância dos ganhos ambientais decorrentes da diminuição da extração de seixo do leito dos rios, proporcionada com a industrialização do ASAC. Essa análise, porém, necessita de um estudo muito específico e seus efeitos financeiros são de difícil mensuração.

\section{Levantamento de custos unitários de produção}

Para se conhecer melhor os custos e estabelecer o preço final para produção do ASAC com maior precisão foi necessário aferir todo o processo produtivo e os custos unitários das máquinas, equipamentos e mão de obra, além de custos indiretos como administração, marketing e vendas, somados aos encargos e lucro almejado pelo setor. A fim de viabilizar essa análise, foi concebida uma indústria cerâmica hipotética, a partir do estudo dos processos produtivos das cerâmicas de Iranduba e Manacapuru, representativas do polo oleiro no Estado do Amazonas, sendo os custos da cadeia produtiva dividida nos seguintes processos: obtenção da matéria prima, homogeneização/conformação e calcinação. 


\section{Obtenção da matéria-prima}

Em relação ao processo de obtenção da matéria prima, as etapas a serem consideradas, que podem variar de acordo com o tipo de jazida, são: remoção da camada vegetal, retirada da camada superficial de solo, extração da argila (escavação e carga), transporte e estocagem. Particularmente, a distância de transporte é uma variável com grande importância na cadeia produtiva, razão pela qual é fundamental que as instalações físicas das indústrias situem-se o mais próximo possível das jazidas de argila, o que não é de grande dificuldade diante da abundância dessa matéria prima na região. Os custos dessas operações podem ser obtidos com as composições unitárias dos equipamentos envolvidos na operação, tendo sido realizado de acordo com o preconizado no manual de custos rodoviários [11].

\section{Homogeneização e conformação}

Para análise do processo de homogeneização e conformação, estabeleceu-se uma planta produtiva teórica com os principais equipamentos de uma indústria de cerâmica vermelha, interligados por correias transportadoras, nessa ordem: caixão alimentador, desintegrador, misturador horizontal, laminador e extrusora (maromba) a vácuo. Após essa definição, pesquisou-se no mercado o custo de aquisição de equipamentos novos, bem como suas características técnicas, dados a partir dos quais foram calculados os custos horários e produtividade dos equipamentos. Na determinação do custo horário utilizaram-se os procedimentos pre-conizados pelo DNIT, particularmente aqueles referentes aos equipamentos rodoviários. Nessa metodologia as parcelas que compõem o custo horário são depreciação e juros (custo de propriedade), consumo energético e operador (custo de operação) e custo de manutenção [12]. A depreciação $\left(D_{h}\right)$ é mais acentuada nos primeiros anos de vida do equipamento, mas pode ser calculada, de forma simplificada, considerando-se uma redução linear do valor da máquina ao longo de sua vida, equivalente à diferença entre o valor de aquisição $\left(V_{o}\right)$ e o valor residual $\left(V_{r}\right)$, divididos pela sua vida útil $\left(V_{U}\right)$, conforme mostra a equação A. No caso dos juros $\left(J_{h}\right)$, estes refletem um investimento médio e podem ser calculados segundo a equação B.

$$
\begin{aligned}
& \mathrm{D}_{\mathrm{h}}=\frac{\mathrm{V}_{0}-\mathrm{V}_{\mathrm{r}}}{\mathrm{V}_{\mathrm{U}}} \\
& \mathrm{J}_{\mathrm{h}}=\frac{1_{\mathrm{m}}^{-\mathrm{i}}}{\mathrm{a}} \text {, sendo } \mathrm{I}_{\mathrm{m}}=\left(\mathrm{V}_{0}-\mathrm{V}_{\mathrm{r}}\right) \cdot \frac{(\mathrm{n}+1)}{2 \mathrm{n}}+\mathrm{V}_{\mathrm{r}}
\end{aligned}
$$

na qual $n$ e $a$ são vida útil em anos e a quantidade estimada em horas de trabalho por ano, respectivamente.

Para se determinar os custos de operação, contabilizase o consumo energético, determinado diretamente pela multiplicação da potência do motor $(\mathrm{kW} / \mathrm{h})$ pela tarifa local, e o custo do operador pelo cálculo do salário por hora, acrescentando-se aí os encargos sociais. Quanto aos custos de manutenção $\left(M_{h}\right)$, esses normalmente são calculados pela aplicação de um coeficiente $(k)$ indicado pela equação C.

$$
\mathrm{M}_{\mathrm{h}}=\mathrm{k} \cdot \frac{\mathrm{Vo}}{\mathrm{n} \cdot \mathrm{a}}
$$

Com cada uma dessas parcelas pode-se calcular o custo horário produtivo e o improdutivo. Para a composição do custo horário produtivo, somam-se os custos de propriedade, de operação e manutenção. $\mathrm{Na}$ composição do custo improdutivo, somam-se apenas os custos de propriedade e a mão de obra.

\section{Calcinação (sinterização)}

$\mathrm{Na}$ calcinação reside atualmente uma das principais dificuldades do processo produtivo do ASAC, pois nesse caso os atuais fornos usados pelas indústrias de cerâmica vermelha não são os mais adequados em razão da dificuldade de seu acondicionamento sobre grelhas, bem como da possibilidade de agregação das partículas em decorrência da pressão a que estariam submetidas em fornos estáticos. Para evitar esses problemas poderiam ser utilizados, por exemplo, fornos cilíndricos rotativos. Diante da inexistência de fornos similares nas indústrias tradicionais de cerâmica vermelha foi realizado um estudo teórico, segundo a literatura técnica, relativo à quantidade de combustível necessário ao processo de calcinação, obtida a partir da determinação da energia líquida propriedades térmicas do material em conjunto com a eficiência térmica. Esse insumo deve constituir-se na maior parcela de custo unitário, de acordo com dados estatísticos do setor [13].

\section{Produção para Consumo Próprio}

No caso da produção do agregado para execução direta de obras, como as rodoviárias, algumas considerações devem ser realizadas para a comparação dos custos. Caso não exista agregado convencional nas proximidades da obra, $\mathrm{o}$ que é a situação mais comum no estado do Amazonas deve ser acrescido ao seixo o custo do transporte comercial. Por outro lado, em relação à produção do agregado sinterizado, deverão ser ponderados apenas os custos diretos, o que pode lhe conferir grande vantagem financeira. Obviamente, para isso, necessita-se de jazidas de argila nas proximidades da obra, o que costuma ocorrer, como, por exemplo, no caso do Município de Manaus e das regiões no entorno da BR -319 [5].

\section{RESULTADOS E DISCUSSÃO}

\section{Análise preliminar}

Como resultado da caracterização do ASAC, verificou-se que sua densidade aparente no estado solto é de $1.062 \mathrm{~kg} / \mathrm{m}^{3}$ [15]. Os tijolos cerâmicos de oito furos, com medidas aproximadas de $9 \mathrm{~cm} \mathrm{x} 19 \mathrm{~cm} \mathrm{x} 19$ $\mathrm{cm}$, apresentaram para massa o valor médio de $2030 \mathrm{~g}$. Dessa forma, $1 \mathrm{~m}^{3}$ de ASAC equivale a 523,15 unidades dos tijolos. Assim, alterando-se apenas a conformação 


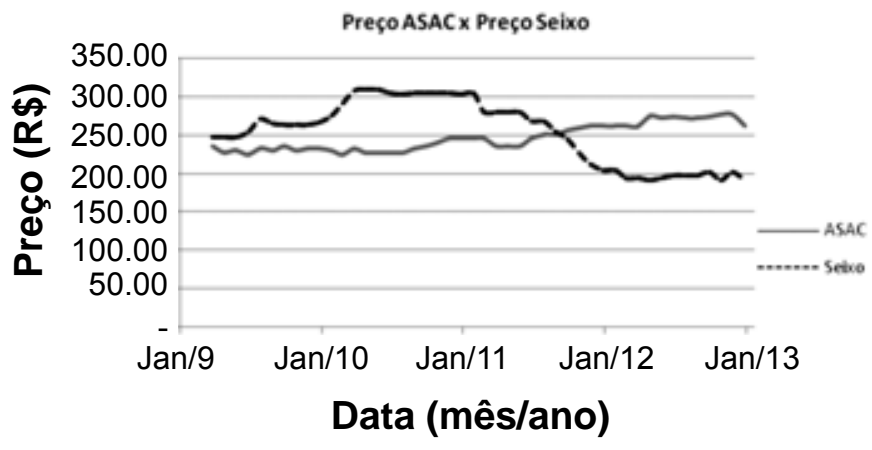

Figura 1: Paralelo entre os preços do ASAC equivalente e seixo rolado. Fonte: SINAPI.

[Figure 1: Parallel between the prices of ASAC equivalent and boulder. Source: SINAPI.]

do produto final, mantidas todas as demais variáveis e condições, bem como considerando o preço unitário do tijolo de referência (SINAPI), obtém-se o preço de $1 \mathrm{~m}^{3}$ de ASAC equivalente, que pode ser comparado com o preço do seixo rolado em Manaus/AM. Além disso, para que possam ser analisadas também as questões sazonais, elaborou-se a Fig. 1, na qual os resultados estão dispostos ponderando-se as variações mensais entre janeiro de 2009 e janeiro de 2013.

Analisando-se os resultados dispostos na Fig. 1 observa-se que o preço do ASAC equivalente não teria sofrido variações bruscas, mas apresentaria aumento progressivo. Por outro lado, o preço do seixo apresenta grandes variações, constatando-se uma queda expressiva nos últimos dois anos. Dessa forma, o ASAC, que apresentaria preço abaixo do seixo desde o início da série até setembro de 2011, no momento não apresentaria vantagem financeira frente ao agregado tradicional local. Porém, há outras questões que devem ser consideradas, como a demanda reprimida por agregado graúdo, pois em Manaus/AM não se costuma usar Concreto Asfáltico - CA para pavimentação das vias públicas, diante da escassez desses agregados, o que implica em deterioração precoce da malha viária. Por questões específicas de economia, uma maior demanda sem aumento de oferta leva a acréscimos de preços. É o cenário que seria criado caso o poder público local passasse a exigir o uso do

Tabela I - Composição de preços para extração da matéria prima.

[Table I - Composition prices for extraction of raw materials.]

\begin{tabular}{|c|c|c|c|c|c|c|c|}
\hline TIPO & CÓDIGO & DESCRIÇÃO & UN. & COEF. & QUANT. & $\begin{array}{l}\text { PREÇO } \\
\text { UNIT. }\end{array}$ & $\begin{array}{l}\text { PREÇO } \\
\text { TOTAL }\end{array}$ \\
\hline \multicolumn{8}{|c|}{ equipamentos: } \\
\hline EQU & E001 & $\begin{array}{l}\text { Trator de Esteiras - com lâmina } \\
(67 \mathrm{~kW}) \text { (produtivo) }\end{array}$ & $\mathrm{h}$ & 1,0000 & 1,00 & 113,85 & 113,85 \\
\hline EQU & E001 & $\begin{array}{l}\text { Trator de Esteiras - com lâmina } \\
(67 \mathrm{~kW}) \text { (improdutivo) }\end{array}$ & $\mathrm{h}$ & 0,0000 & 1,00 & 22,39 & - \\
\hline EQU & E016 & $\begin{array}{l}\text { Carregadeira de Pneus - } \\
1,91 \mathrm{~m}^{3}(113 \mathrm{~kW}) \text { (produtivo) }\end{array}$ & $\mathrm{h}$ & 0,5600 & 1,00 & 115,37 & 64,61 \\
\hline EQU & E016 & $\begin{array}{l}\text { Carregadeira de Pneus - } \\
1,91 \mathrm{~m}^{3}(113 \mathrm{~kW}) \text { (improdutivo) }\end{array}$ & $\mathrm{h}$ & 0,4400 & 1,00 & 22,39 & 9,85 \\
\hline \multicolumn{8}{|c|}{ Mão de obra: } \\
\hline MO & T501 & Encarregado de turma & $\mathrm{h}$ & 1,0000 & 1,00 & 23,67 & 23,67 \\
\hline \multirow[t]{2}{*}{$\mathrm{MO}$} & $\mathrm{T} 701$ & Servente & $\mathrm{h}$ & 1,0000 & 3,00 & 7,67 & 23,01 \\
\hline & & $\begin{array}{l}\text { Adc.M.O. - Ferramentas: } \\
(20,51 \%)\end{array}$ & & & & & 9,57 \\
\hline \multicolumn{8}{|c|}{ Atividades Auxiliares: } \\
\hline & & $\begin{array}{l}1 \text { A } 0110001 \text { - Limpeza camada } \\
\text { vegetal em jazida (const. e restr.) }\end{array}$ & $\mathrm{m}^{2}$ & & 0,70 & 0,81 & 0,57 \\
\hline & & $\begin{array}{l}\text { 1 A } 0110501 \text { - Expurgo de } \\
\text { jazida (const. e restr.) }\end{array}$ & $\mathrm{m}^{3}$ & & 0,20 & 4,40 & 0,88 \\
\hline \multicolumn{8}{|c|}{ Resumo da composição } \\
\hline & & Equipamentos (para $50 \mathrm{~m}^{3}$ ) & & & & & 188,31 \\
\hline & & Mão de obra (para $50 \mathrm{~m}^{3}$ ) & & & & & 46,68 \\
\hline & & Atividades Auxiliares & & & & & 1,45 \\
\hline \multicolumn{3}{|c|}{ Custo total $\left(\right.$ por $\left.\mathrm{m}^{3}\right)$} & & & & & 6,34 \\
\hline
\end{tabular}

Observações:

Produção da equipe: $50 \mathrm{~m}^{3}$.

Os preços dos equipamentos incluem seus operadores. 
agregado graúdo na massa asfáltica. Ou seja, mesmo diante dessa desvantagem financeira inicial, a produção do agregado artificial poderia garantir seu fornecimento em quantidade, com estabilidade de preço, suficiente para suprir a demanda reprimida por esse material, proporcionando melhoria técnica na pavimentação da malha viária urbana com diversos ganhos diretos e indiretos.

\section{Levantamento de custos unitários de produção}

Esse levantamento foi dividido de acordo com os processos realizados dentro da cadeia produtiva definida anteriormente: obtenção da matéria prima, homogeneização/conformação e calcinação. A seguir estão dispostos os resultados.

\section{Obtenção da matéria-prima}

Na determinação desses custos, conforme já mencionado, foram utilizados parâmetros de obras rodoviárias, diante da similaridade das operações no que diz respeito à exploração de jazidas. Dessa forma, adaptou-se a composição de custo unitário para o serviço "1 A 0111101 - Esc. e carga material de jazida (consv)" [11], com a exclusão da motoniveladora, por ser dispensável para o caso em estudo. Assim, obtevese o valor de $\mathrm{R} \$ 6,34$ para extração de $1 \mathrm{~m}^{3}$ (Tabela I), desconsiderando o transporte.

Em relação ao transporte da matéria prima, considerouse a velocidade média de $40 \mathrm{~km} / \mathrm{h}$ e a utilização de um caminhão basculante com capacidade para $5 \mathrm{~m}^{3}$, parâmetros equivalentes aos da composição de preços do serviço "3 $S 09$ 00100 - Transporte local c/ basc. $5 \mathrm{~m}^{3}$ em rodov. não pav." [11], que indica o custo de $\mathrm{R} \$ 0,72$ (setenta e dois centavos) por t.km. Avaliando-se para uma distância média de $5 \mathrm{~km}$, dentro da concepção da indústria teórica definida no início da análise, e adotando-se peso específico natural de $17 \mathrm{kN}$ [16], resulta o custo de $\mathrm{R} \$ 6,12$ ) por metro cúbico de argila transportada. Até aqui, a matéria prima totaliza R\$ 12,46 por metro cúbico de argila extraída. Acrescentando-se a esse o valor o percentual de $2 \%$ correspondente a Compensação Financeira pela Exploração de Recursos Minerais - CFEM, tem-se o custo total dessa etapa no valor de $\mathrm{R} \$ 12,71$ por metro cúbico.

\section{Homogeneização/Conformação}

Relativo a esse processo e observando-se o método

Tabela II - Custo horário dos equipamentos.

[Table II - Hourly cost of equipment.]

\begin{tabular}{lcccccccc}
\hline \multicolumn{1}{c}{ Equipamento } & $\begin{array}{c}\text { Valor de } \\
\text { Aquisição } \\
(\mathrm{R} \$)\end{array}$ & $\begin{array}{c}\text { Depreciação } \\
(\mathrm{Dh})\end{array}$ & $\begin{array}{c}\text { Juros } \\
(\mathrm{Jh})\end{array}$ & $\begin{array}{c}\text { Potência } \\
(\mathrm{kW})\end{array}$ & $\begin{array}{c}\text { Energia } \\
\text { elétrica } \\
(\mathrm{R} \$ / \mathrm{h})\end{array}$ & $\begin{array}{c}\text { Manutenção } \\
(\mathrm{Mh})\end{array}$ & $\begin{array}{c}\text { Custo } \\
\text { Produtivo } \\
(\mathrm{R} / \$)\end{array}$ & $\begin{array}{c}\text { Custo } \\
\text { Improdutivo } \\
(\mathrm{R} / \$)\end{array}$ \\
\hline Caixão alimentador & $55.600,00$ & 2,41 & 1,91 & 9,56 & 5,42 & 1,60 & 11,34 & 7,44 \\
Desintegrador & $66.700,00$ & 2,89 & 2,29 & 22,07 & 12,51 & 1,92 & 19,61 & 12,39 \\
Misturador & $91.100,00$ & 3,94 & 3,13 & 36,78 & 20,85 & 2,63 & 30,54 & 19,09 \\
Laminador & $91.100,00$ & 3,94 & 3,13 & 47,81 & 27,10 & 2,63 & 36,80 & 22,69 \\
Maromba à vácuo & $211.100,00$ & 9,13 & 7,25 & 128,71 & 72,96 & 6,09 & 95,43 & 58,45 \\
Bomba de vácuo & $7.500,00$ & 0,32 & 0,26 & 7,36 & 4,17 & 0,22 & 4,97 & 2,99 \\
Cortador automático & $31.100,00$ & 1,35 & 1,07 & 1,47 & 0,83 & 0,90 & 4,14 & 2,89 \\
Esteira transportadora & $11.000,00$ & 0,48 & 0,38 & 2,94 & 1,67 & 0,32 & 2,84 & 1,82 \\
\hline
\end{tabular}

Observações:

Taxa de juros anual de mercado $\quad 12,00$

Tarifa energia elétrica - consumo (R\$/kWh) 0,24 [19]Tarifa energia elétrica - demanda $(R \$ / \mathrm{kW}) 52,29$ [19]

Coeficiente manutenção 0,60

Tabela III - Coeficientes de produtividade dos equipamentos.

[Table III - Coefficients of equipment productivity.]

\begin{tabular}{llccccc}
\hline \multicolumn{1}{c}{ Equipamento } & Referência & $\begin{array}{c}\text { Capacidade } \\
\text { nominal (t) }\end{array}$ & $\begin{array}{c}\text { Fator de } \\
\text { Eficiência }\end{array}$ & $\begin{array}{c}\text { Capacidade } \\
\text { Final }\end{array}$ & Produtivo & Improdutivo \\
\hline Caixão alimentador & MN6/1000 & 40,0 & 0,75 & 30,0 & 0,70 & 0,30 \\
Desintegrador & NTB-600'C' & 30,0 & 0,75 & 22,5 & 0,93 & 0,07 \\
Misturador & MTR-4'B' & 40,0 & 0,75 & 30,0 & 0,70 & 0,30 \\
Laminador & MN-700 & 28,0 & 0,75 & 21,0 & 1,00 & - \\
Maromba à vácuo & NTB5 & 30,0 & 0,75 & 22,5 & 0,93 & 0,07 \\
Bomba de vácuo & MN-2G & 30,0 & 0,75 & 22,5 & 0,93 & 0,07 \\
Cortador automático & VB36 & 30,0 & 0,75 & 22,5 & 0,93 & 0,07 \\
Esteira transportadora & $24{ }^{\prime} \times 16 \mathrm{~m}$ & 30,0 & 0,75 & 22,5 & 0,93 & 0,07 \\
\hline
\end{tabular}

Observação: Produção da equipe: $21 t$ 
Tabela IV - Composição de custo unitário para homogeneização/conformação (t).

[Table IV - Composition of unit cost for homogenization/conformation ( $t)$.]

\begin{tabular}{|c|c|c|c|c|c|c|c|c|c|}
\hline \multirow{2}{*}{ tipo } & \multirow{2}{*}{ código } & \multirow{2}{*}{ descrição } & \multirow[b]{2}{*}{ un } & \multirow{2}{*}{ quant. } & \multicolumn{2}{|c|}{ coeficiente } & \multicolumn{2}{|c|}{ preço unitário } & \multirow{2}{*}{$\begin{array}{c}\text { preço } \\
\text { total }\end{array}$} \\
\hline & & & & & produtivo & improd. & produtivo & improd. & \\
\hline \multicolumn{10}{|c|}{ Equipamentos: } \\
\hline EQU & MN6/1000 & Caixão alimentador & $\mathrm{h}$ & 1 & 0,7000 & 0,3000 & 11,34 & 7,44 & 7,94 \\
\hline EQU & NTB-600'C' & Desintegrador & $\mathrm{h}$ & 1 & 0,9333 & 0,0667 & 19,61 & 12,39 & 18,30 \\
\hline EQU & MTR-4'B' & Misturador & $\mathrm{h}$ & 1 & 0,7000 & 0,3000 & 30,54 & 19,09 & 21,38 \\
\hline EQU & MN-700 & Laminador & $\mathrm{h}$ & 1 & 1,0000 & 0,0000 & 36,80 & 22,69 & 36,80 \\
\hline EQU & NTB5 & Maromba à vácuo & $\mathrm{h}$ & 1 & 0,9333 & 0,0667 & 95,43 & 58,45 & 89,07 \\
\hline EQU & $\mathrm{MN}-2 \mathrm{G}$ & Bomba de vácuo & $\mathrm{h}$ & 1 & 0,9333 & 0,0667 & 4,97 & 2,99 & 4,64 \\
\hline EQU & VB36 & Cortador automático & $\mathrm{h}$ & 1 & 0,9333 & 0,0667 & 4,14 & 2,89 & 3,87 \\
\hline EQU & $24 " x 6 \mathrm{~m}$ & Esteira transportadora & $\mathrm{h}$ & 4 & 0,9333 & 0,0667 & 2,84 & 1,82 & 10,60 \\
\hline \multicolumn{10}{|c|}{ Mão de obra: } \\
\hline $\mathrm{MO}$ & T501 & Encarregado de turma & $\mathrm{h}$ & 1 & & & 23,67 & & 23,67 \\
\hline $\mathrm{MO}$ & $\mathrm{T} 701$ & Servente & $\mathrm{h}$ & 3 & & & 7,67 & & 23,01 \\
\hline \multicolumn{10}{|c|}{ Resumo da composição } \\
\hline & & Equipamentos (para 21t) & & & & & & & 192,59 \\
\hline & & Mão de obra (para 21t) & & & & & & & 46,68 \\
\hline \multicolumn{5}{|c|}{ Custo total (por tonelada) } & & & & & 11,39 \\
\hline
\end{tabular}

descrito anteriormente, inicialmente calculou-se o custo horário para cada um dos equipamentos, para situação produtiva e improdutiva. Os resultados encontram-se sintetizados na Tabela II:

Estabelecidos os custos horários individuais, necessitase da avaliação da produção, a fim de compor os custos unitários do processamento. Tal análise é realizada a partir da capacidade de produção de cada equipamento, sendo que o de menor capacidade irá definir o resultado do conjunto e, a partir daí, segundo uma simples relação entre a capacidade individual e a do conjunto, estabelece-se a parcela produtiva e a improdutiva para cada maquinário, culminando-se no custo total do processamento. Nas Tabelas III e IV estão dispostos os dados e resultados, de onde se extrai o custo final de $\mathrm{R} \$ 11,39$ (onze reais e trinta e nove centavos) por tonelada de argila homogeneizada/ conformada. Ressalta-se que a análise efetuada para o conjunto de equipamentos propostos nesse item refere-se à massa úmida que, considerando-se produção diária de oito horas e seis dias por semana, resulta em uma produção mensal de 4.032 toneladas.

\section{Calcinação (Sinterização)}

Foi demonstrado que a energia teórica requerida para o processo de sinterização da argila no forno a $30^{\circ} \mathrm{C}$, com $6 \%$ de umidade e temperatura de queima a $950{ }^{\circ} \mathrm{C}$, corresponde a $275 \mathrm{kcal} / \mathrm{kg}$, equivalente a $1.150,60 \mathrm{~kJ} / \mathrm{kg}$ [17]. Igualmente, foi mostrado que se necessita de $142 \mathrm{kcal} / \mathrm{kg}$ para secagem artificial desse material. Assim, o insumo energético líquido para um processo conjunto de secagem-calcinação será igual a $417 \mathrm{kcal} / \mathrm{kg}$, correspondente a $1.744,73 \mathrm{~kJ} / \mathrm{kg}$. Além da energia líquida para o processo de calcinação, necessita-se de outra importante variável a eficiência energética do forno
Tabela V - Características dos fornos da indústria de cerâmica vermelha. Adaptado [18].

[Table $V$ - Features of the furnaces of red ceramic industry. Adapted [18].]

\begin{tabular}{cccc}
\hline $\begin{array}{c}\text { Tipo de } \\
\text { Forno }\end{array}$ & $\begin{array}{c}\text { Consumo } \\
\text { específico } \\
(\mathrm{kJ} / \mathrm{kg})\end{array}$ & $\begin{array}{c}\text { Valor teórico } \\
(\mathrm{kJ} / \mathrm{kg})\end{array}$ & $\begin{array}{c}\text { Eficiência } \\
\text { energética }\end{array}$ \\
Campanha & 3858,1 & 1159,74 & $30 \%$ \\
Abóbada & 2637,6 & 1159,74 & $44 \%$ \\
Hoffmann & 1784,9 & 1159,74 & $65 \%$ \\
Túnel & 1379,4 & 1159,74 & $84 \%$ \\
\hline
\end{tabular}

Tabela VI - Custo do gás natural para calcinação por tonelada de argila.

[Table VI - Cost of natural gas for calcination per tone of clay.]

\begin{tabular}{llr}
\hline Energia & $\mathrm{kJ} / \mathrm{kg}$ & $2.077,06$ \\
Poder calorífico superior & $\mathrm{kJ} / \mathrm{m}^{3}$ & $36.200,00$ \\
Volume de gás natural & $\mathrm{m}^{3} / \mathrm{t}$ & 57,38 \\
Preço do gás natural & $\mathrm{R} \$ \mathrm{~m}^{3}$ & 1,57 \\
Custo total da energia & $\mathrm{R} \$ / \mathrm{t}$ & 90,08 \\
\hline
\end{tabular}

utilizado, contabilizando-se todas as perdas intrínsecas. Essa eficiência varia muito, a depender do tipo e condições do forno. De maneira geral, os fornos utilizados pelas indústrias de cerâmica vermelha podem ser classificados em intermitentes ou contínuos. Aqueles trabalham com ciclos de carga/queima/descarga e estes são os fornos em que há queima constante, sem interrupção para carga e descarga. Como exemplo dos primeiros citados tem-se os fornos de 
campanha e de abóbadas e, dos segundos, fornos Hoffman e túnel [18]. Em razão do tipo de funcionamento, os fornos contínuos apresentam melhor eficiência energética, como apresentado na Tabela V.

Dentro do escopo desse estudo, trabalha-se com a concepção de uma indústria padrão e, dada a importância do processo de calcinação no custo final, bem como da grande demanda que pode ser alcançada com a produção do ASAC, será avaliado um forno contínuo para a seqüência dos cálculos, ou seja, uma eficiência energética de $84 \%$. Portanto, para essa eficiência e o valor líquido demonstrado anteriormente, necessita-se de $2.077,06 \mathrm{~kJ} / \mathrm{kg}$ para $\mathrm{o}$ processo de calcinação. Por outro lado, a fonte energética empregada, em geral, nos fornos da região é, basicamente, a lenha [13]. Esta se constitui em um combustível renovável, quando proveniente de áreas plantadas, mas como não há uma exploração sustentável na região, seu uso não poderá ser incentivado. A melhor alternativa passa a ser o gás natural [14], que apresenta poder calorífico superior igual a $36.200 \mathrm{~J} / \mathrm{m}^{3}$ (valor médio calculado a partir dos limites estabelecidos pelo Regulamento Técnico ANP 2/2008 para a Região Norte), equivalente a $8.652 \mathrm{kcal} / \mathrm{m}^{3}$. Seu preço atual, segundo dados divulgados pela concessionária CIGÁS, Companhia de Gás do Amazonas, é de R\$ 1,57 por metro cúbico. Com esses dados, o custo por tonelada correspondente ao combustível necessário para calcinação será igual a $\mathrm{R} \$ 90,08$ (noventa reais e oito centavos), conforme detalhado na Tabela VI.

Definido o consumo energético, há que se considerarem os custos relativos à propriedade, os operacionais e à manutenção do forno, podendo ser calculados da mesma forma como definido para os equipamentos da linha de processamento da massa argilosa. A dificuldade reside na inexistência de um forno padrão para o processamento definido. De qualquer forma, os princípios são os mesmos de um forno para cerâmica convencional, razão pela qual foram utilizados os dados disponíveis para cálculo dessa parcela do custo. Em pesquisa a empresários do setor, constatou-se que um forno simples (abóbada) custa em torno de R $\$ 65.000,00$, com capacidade para 25.000 unidades de tijolos de oito furos com dimensões $9 \mathrm{~cm} \times 19 \mathrm{~cm} \times 19 \mathrm{~cm}$, girando em média 3 ciclos a cada 15 dias, resultando em uma produção de $0,42 \mathrm{ton} / \mathrm{h}$. Já um forno moderno (semi-contínuo) com capacidade para 40.000 unidades dos mesmos tijolos, média de 3 ciclos de queima a cada 10 dias e 1,13 toneladas por hora, custa $\mathrm{R} \$ 600.000,00$. Com tais informações, obtém-se para o primeiro tipo de forno o custo produtivo por tonelada, sem considerar o combustível, o valor de $\mathrm{R} \$ 9,28$ e para o segundo o montante igual a $\mathrm{R} \$ 10,93$. Este último valor será o utilizado na composição final, por representar o tipo de forno que melhor se aproxima das premissas iniciais indicadas neste estudo. Assim, o custo com o processo de sinterização totalizou $\mathrm{R} \$ 101,01$.

\section{Custos indiretos}

Além dos procedimentos já detalhados, devem ser levados em consideração outros custos até então não contabilizados, quais sejam, aqueles relacionados às instalações físicas (terreno e galpões), administração/vendas, lucro almejado e carga tributária. Em relação às instalações físicas, necessitase de área para abrigo dos equipamentos que fazem parte do processo de homogeneização/conformação, assim como para estocagem de material, tanto da matéria prima quanto do produto final antes da queima. Desta feita, a área necessária para um conjunto de equipamentos perfaz cerca de $100 \mathrm{~m}^{2}$ e para estocagem coberta da matéria prima e do produto antes da queima considerando-se a capacidade para acúmulo de três dias de produção, igual a $200 \mathrm{~m}^{2}$, totalizando $300 \mathrm{~m}^{2}$ de área. Consultando-se o Custo Unitário Básico (CUB) de construção de galpão industrial, divulgado mensalmente em www.cub.org.br, obtêm-se o valor de R\$ 633,93 por metro quadrado, para o mês de junho/2012, no estado do Amazonas. Tal valor aplicado para a área estimada perfaz R \$ 190.179,00. Como no CUB não estão inclusos alguns elementos construtivos, como as fundações e as despesas indiretas, estes devem ser calculados à parte, mas normalmente equivalem a cerca de $30 \%$ de acréscimo, culminando em R $\$ 247.232,70$. No caso do terreno, pesquisado em anúncios nos classificados locais, tem-se o preço de $\mathrm{R} \$ 40,00$ por metro quadrado. No caso em tela, tomando-se o dobro da área do galpão $\left(600 \mathrm{~m}^{2}\right)$, a aquisição se daria por $\mathrm{R} \$ 24.000,00$. Para cálculo da parcela do custo da área (terreno e galpão industrial) inerente a produção unitária pode-se aplicar a mesma metodologia do cálculo horário dos equipamentos, ou seja, considerando-se a depreciação e os juros relacionados ao custo do investimento. $\mathrm{O}$ terreno, em geral, não apresenta depreciação, no entanto, avaliando-se seu pequeno peso no valor concernente à área, será mantido no total, como uma margem de segurança. Utilizando-se então os valores determinados anteriormente, para uma vida útil de 300 meses (Instrução Normativa SRF 162, de $31 / 12 / 1998$ ), valor residual de $10 \%$, produção horária de 21 toneladas e taxa anual de juros de mercado de $12 \%$, obtêmse o resultado de $\mathrm{R} \$ 0,65$ por tonelada de material úmido

Tabela VII - Preço para produção do ASAC por tonelada. [Table VII - Price for production per tone of ASAC.]

\begin{tabular}{lcccc}
\hline Descrição & Unidade & Quantidade & $\begin{array}{c}\text { Valor } \\
\text { unitário }\end{array}$ & $\begin{array}{c}\text { Valor } \\
\text { total }\end{array}$ \\
\hline Matéria-prima & $\mathrm{m}^{3}$ & 0,83 & 12,71 & 11,25 \\
Homogeneização & $\mathrm{t}$ & 1,25 & 11,39 & 15,13 \\
Calcinação & $\mathrm{t}$ & 1,00 & 101,01 & 107,27 \\
$\begin{array}{l}\text { Instalações } \\
\text { fisicas }\end{array}$ & $\mathrm{t}$ & 1,25 & 0,65 & 0,86 \\
$\begin{array}{l}\text { Administração/ } \\
\text { Vendas }\end{array}$ & $\%$ & & & \\
$\begin{array}{l}\text { Impostos } \\
\text { Lucratividade }\end{array}$ & $\%$ & & 5,30 & 11,02 \\
Sobtotal & $\%$ & & 20,00 & 41,58 \\
\multicolumn{1}{c}{ Preço Revenda (10\% de acréscimo) } & & 20,00 \\
\hline
\end{tabular}




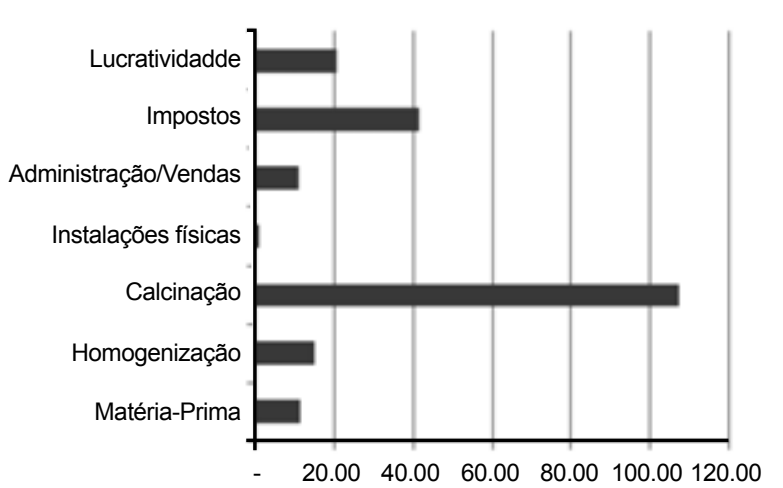

Figura 2: Valores por etapa do preço previsto para o agregado sinterizado.

[Figure 2: Values by stage of expected price for the sintered aggregate.]

processado. Por fim, os custos com administração/vendas e impostos indicativos a uma empresa de porte médio do setor giram em torno de $5,3 \%$ e $20 \%$ do total, respectivamente [17]. No tocante à lucratividade, $10 \%$ é considerada uma taxa atrativa para retorno do investimento.

Com todos esses dados, calcula-se o custo de produção e o preço final de comercialização do ASAC, perfazendo o preço comercial por tonelada de $\mathrm{R} \$ 228,68$, podendo variar de acordo com as margens de lucro almejadas pelo fabricante e comerciante final (Tabela VII). Ponderando a massa específica de $1.062 \mathrm{~kg} / \mathrm{m}^{3}$ o preço por $\mathrm{m}^{3}$ será de $\mathrm{R} \$$ 242,86 .

Essa análise detalhada resultou em um preço inferior ao obtido no exame preliminar, mas ainda assim encontra-se $24 \%$ acima do preço do seixo rolado para o mês de junho, cabendo aqui as mesmas observações levantadas quando daquela análise. Outras importantes questões, porém de difícil mensuração, são os ganhos ambientais decorrentes da redução da extração de seixo do leito dos rios com a produção do agregado sinterizado, além da maior segurança no seu fornecimento, tendo em vista a abundância da argila na região em pauta. Ressalta-se que, dentro dos custos até a revenda, o processo de calcinação apresenta grande importância, correspondente a mais de $50 \%$ do total (Fig. 2), demonstrando que a esse processo deve ser dada especial atenção, sobretudo no tocante aos fornos, pois sua eficiência energética pode ser determinante em relação à viabilidade econômica.

\section{Produção para consumo próprio}

Algumas considerações são necessárias para fins de comparação entre o preço do seixo comercial e o custo de produção do agregado sinterizado, quando a produção deste se destina diretamente para a obra, ou seja, não possua finalidade comercial direta. No tocante a execução de uma obra em um local isolado ou a grandes distâncias, como ocorre, em geral, com a construção de rodovias, as considerações são: a) Relativo ao seixo, devem ser acrescidos custos com transportes, caso a obra seja executada fora do perímetro urbano; e b) Concernente ao agregado sinterizado, as distâncias não são relevantes, posto que o mesmo poderá ser confeccionado no próprio canteiro de obras por usinas móveis, como sucede com as centrais de britagem ou usinas de asfalto, e além disso apenas os custos diretos de produção deverão compor seu custo total, como adiante detalhado.

\section{Custo do seixo incluindo transporte}

$\mathrm{O}$ transporte do seixo comercial, segundo a metodologia constante no SICRO2, é feito por caminhões basculantes e seu valor unitário é dado em t.km, ou seja, um valor por tonelada e por quilômetro a ser percorrido. Para rodovia não pavimentada a composição correspondente ao código "1 A 0000191 - Transporte comercial c/ basc. $\quad 10 \mathrm{~m}^{3}$ rod. não pav.", cujo custo unitário, para março de 2012 no Estado do Amazonas, incidiu no valor de R \$ 0,53. Para uma distância média de transporte de $100 \mathrm{~km}$, por exemplo, o custo por tonelada será de $\mathrm{R} \$ 53,00$. Considerando-se para o seixo uma massa específica de $1,8 \mathrm{t} / \mathrm{m}^{3}$ [15], o custo para transporte de $1 \mathrm{~m}^{3}$ de seixo resultará em $\mathrm{R} \$ 95,40$. Somandose a esse valor o preço de venda em Manaus/AM igual a R\$ 194,51 , obtém-se seu custo total no local da obra no valor de $\mathrm{R} \$ 289,91$.

\section{Custo do agregado sinterizado}

No caso da produção do agregado sinterizado para consumo na obra, não comporão seu custo direto as seguintes parcelas: Administração/Vendas, Impostos e Lucratividade. Além disso, há que se ponderar a indisponibilidade de gás natural, combustível incluído no cálculo anterior. A alternativa energética poderá, então, ser o óleo combustível $1 \mathrm{~A}$, com poder calorífico por quilograma similar ao do gás

Tabela VIII - Custo do óleo combustível para calcinação por tonelada de argila.

[Table VIII - Cost of fuel oil for calcining per ton clay.]

\begin{tabular}{lcr}
\hline Energia & $\mathrm{kJ} / \mathrm{kg}$ & $2.077,06$ \\
Poder calorífico superior & $\mathrm{kJ} / \mathrm{L}$ & $40.794,00$ \\
Volume de óleo & $\mathrm{kg} / \mathrm{t}$ & 50,92 \\
Preço do óleo combustível & $\mathrm{R} \$ / \mathrm{L}$ & 1,50 \\
Custo total da energia & $\mathrm{R} \$ / \mathrm{t}$ & 76,37 \\
\hline
\end{tabular}

Tabela IX - Custo para produção do ASAC por tonelada. [Table IX - Cost of production per tone of ASAC.]

\begin{tabular}{ccccc}
\hline Descrição & Unidade & Quantidade & $\begin{array}{c}\text { Valor } \\
\text { unitário }\end{array}$ & $\begin{array}{c}\text { Valor } \\
\text { total }\end{array}$ \\
\hline Matéria-Prima & $\mathrm{m}^{3}$ & 0,83 & 12,71 & 11,25 \\
Homogeneização & $\mathrm{t}$ & 1,25 & 11,39 & 15,13 \\
Calcinação & $\mathrm{t}$ & 1,00 & 87,30 & 92,71 \\
Instalações & $\mathrm{t}$ & 1,25 & 0,65 & 0,86 \\
$\quad$ físicas & & & & 119,94 \\
$\quad$ Custo total & & & & \\
\hline
\end{tabular}


natural e custo unitário cotado pelo SICRO. Considerandose a presente alternativa para o processo de calcinação, tem-se o valor de R \$ 76,37 como demonstrado na Tabela VIII. Somado a esse valor os custos relacionados ao forno, definidos anteriormente, totalizam $\mathrm{R} \$ 87,30$ para esse processo. Com o custo do processo de sinterização, obtémse o montante de R $\$ 119,94$ para custo total de produção do ASAC, por tonelada, segundo os dados dispostos na Tabela IX. Tal valor equivale a $\mathrm{R} \$ 127,38$ por metro cúbico.

Em suma, considerando-se uma distância média de transporte para o seixo comercial de $100 \mathrm{~km}$ o mesmo chegará à obra por $\mathrm{R} \$ 289,91$ por metro cúbico, ao passo que a produção local de quantidade equivalente de agregado sinterizado resultaria em $\mathrm{R} \$ 127,38$, custo $56 \%$ inferior. Portanto, à medida que a distância média de transporte do seixo acresce a vantagem financeira para a produção local do ASAC acende linearmente (Tabela X). Igualmente, independente da distância de transporte, a produção do ASAC já começa com uma vantagem de $34,51 \%$. Para melhor visualização dos resultados finais, os mesmos

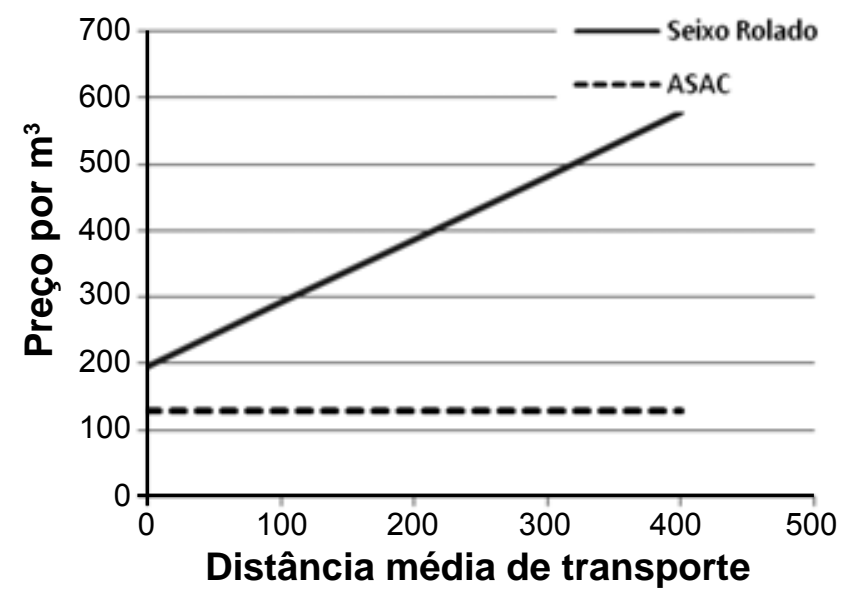

Figura 3: Comparativo entre preço do seixo comercial e custo do ASAC para consumo direto na obra.

[Figure 1: Comparative between price of commercial boulder and ASAC cost for direct consumption in the work.]

Tabela X - Comparativo entre preço do seixo comercial e custo do ASAC para consumo direto na obra de acordo com as distâncias médias de transporte.

[Table X - Comparative between price of commercial boulder and ASAC cost for direct consumption in the work according to the average distances of transport.]

\begin{tabular}{ccccc}
\hline \multirow{2}{*}{$\begin{array}{c}\text { Distância } \\
\text { média de } \\
\text { transporte }\end{array}$} & \multicolumn{2}{c}{ Custo na obra } & \multicolumn{2}{c}{ Diferença } \\
\cline { 2 - 5 } & $\begin{array}{c}\text { Seixo } \\
\text { Rolado }\end{array}$ & ASAC & R\$ & $\%$ \\
\hline 0 & 194,51 & 127,38 & $-67,13$ & $-34,51$ \\
100 & 289,91 & 127,38 & $-162,53$ & $-56,06$ \\
200 & 385,31 & 127,38 & $-257,93$ & $-66,94$ \\
300 & 480,71 & 127,38 & $-353,33$ & $-73,50$ \\
400 & 576,11 & 127,38 & $-448,73$ & $-77,89$ \\
\hline
\end{tabular}

encontram-se dispostos em paralelo no gráfico ilustrado na Fig. 3.

\section{CONCLUSÃO}

Para produção do agregado sinterizado de argila calcinada, o custo com a calcinação representa grande parcela no processo produtivo, razão pela qual deve ser dada especial atenção a essa etapa, sobretudo no tocante à escolha e operação dos fornos, cuja eficiência energética mostra grande variação e pode definir a viabilidade econômica. Com finalidades comerciais, nas condições atuais e dentro dos parâmetros estabelecidos neste estudo, a produção do agregado sinterizado indicou um preço $24 \%$ acima, relativo ao seixo rolado. Mesmo diante dessa desvantagem financeira inicial, quando comparados diretamente os preços, a produção do agregado artificial poderia garantir seu fornecimento em quantidade, com estabilidade de preço, suficiente para suprir a demanda reprimida por esse material existente na cidade de Manaus, AM, cuja malha viária sofre com degradação precoce diante da falta de agregado graúdo na composição da massa asfáltica, o que proporcionaria melhoria técnica na pavimentação com aumento da vida útil dessas obras, diminuição dos serviços manutenção e maior segurança e conforto aos usuários. Esses ganhos têm reflexo direto no custo das obras, mas dependem de trabalho específico a fim de ser quantificado e expressado em termos financeiros. Ao considerar-se a produção para consumo próprio, ou seja, para aplicação direta na obra, como costuma acontecer durante a construção de rodovias, o custo para produção do ASAC apresentou-se, no momento da avaliação, 34\% abaixo do preço do seixo rolado. Essa vantagem acresce à medida que se aumenta a distância de transporte, chegando a um percentual inferior da ordem de $56 \%$ e $77 \%$ para uma distância média $100 \mathrm{~km}$ e $400 \mathrm{~km}$, respectivamente. Em suma, no momento não é viável financeiramente a produção de ASAC para fornecimento ao mercado de Manaus, quando comparados diretamente os preços. Levados em consideração outros fatores, como a questão da demanda reprimida e da possibilidade de melhoria técnica dos pavimentos urbanos, questão de grande importância atual diante da precária situação da malha viária da cidade de Manaus, AM, a conclusão pode ser outra, mas depende de decisões governamentais, que possuem poder de fomento e de exigência da melhoria técnica dos serviços de pavimentação. Já com foco na produção para consumo próprio, caso das obras rodoviárias, a produção do agregado artificial mostra-se com grande vantagem frente ao agregado convencional, justificando investimento na sua produção. Por fim, ressalta-se que estudos de preço não podem assumir caráter estático, mas devem ser realizados continuamente, para que as mudanças de cenário sejam refletidas na medida em que os cenários mudem, como as alterações de preços dos insumos, avanços tecnológicos etc. Para essa análise contínua, a metodologia de custos apresentada no presente trabalho pode ser aplicada não apenas para o Agregado Sinterizado de Argila Calcinada, mas para qualquer produto 
de cerâmica vermelha que usa o mesmo processo de confecção (obtenção da matéria prima, homogeneização/ conformação e calcinação).

\section{REFERÊNCIAS}

[1] L. B. Bernucci, L. M. G. Motta, J. A. P. Ceratti, J. B. Soares, "Pavimentação Asfáltica: Formação Básica para Engenheiros", $3^{\text {a }}$ reimp., Petrobrás: ABEDA, Rio de Janeiro, RJ (2010).

[2] A. Vieira, "Reunião Anual de Pavimentação", Brasília, Manaus Editora 32 (2000) cd-rom.

[3] R. R. Nascimento, Utilização de Agregados de Argila Calcinada em Pavimentação; Uma Alternativa para o Estado do Acre, Diss. Mestrado, Instituto Alberto Luiz Coimbra de Pós-graduação e Pesquisa de Engenharia, Universidade Federal do Rio de Janeiro, Rio de Janeiro, RJ (2005).

[4] C. A. Frota, C. L. Silva, F. R. G. Nunes, "Jornadas LusoBrasileiras de Pavimentos: Políticas e Tecnologias", Recife 5 (2006) cd-rom.

[5] C. A. Frota, F. R. G. Nunes, C. L. Silva, D. M. Melo, M. G. R. Santos, Cerâmica 53, 327 (2007) 255.

[6] R. A. Santos, A. Vieira, J. R. M. S. Oliveira, L. A. V. Carneiro. "Reunião Anual de Pavimentação/Encontro Nacional de Conservação Rodoviária", Manaus 38 (2007) cd-rom.

[7] F. R. G. Nunes, C. L. C. Silva, C. A. Frota, Cerâmica 55, 336 (2009) 425.

[8] C. L. A. Silva, C. L. Silva, E. P. Rebelo, C. A. Frota, Estudos Tecnológicos 5 (2009) 374.

[9] R. R. Sarges, A. C. R. Nogueira, C. A. Frota, C. L. Silva,
Braz. Geographical J.: Geosci. Humanities Res. Medium 1 (2010) 33.

[10] Caixa Econômica Federal, Sistema Nacional de Pesquisa de Custos e Índices da Construção Civil - SINAPI, 01/2011-06/2012.

[11] DNIT - Departamento Nacional de Infra-Estrutura de Transportes, Sistema de Custos Rodoviários 2 (Março de 2012).

[12] A. D. Mattos, Construção Mercado 72 (2007) 34.

[13] NEAPL/AM "Plano de Desenvolvimento Preliminar - APL de Base Mineral Cerâmico-Oleiro", Secretaria de Estado de Planejamento e Desenvolvimento Econômico SEPLAN (2009).

[14] A. C. L. Silva, E. F. Cartaxo, T\&C Amazônia 22 (2012) 50.

[15] C. L. Silva, Módulo Dinâmico de Misturas Asfálticas Confeccionadas com Agregados Sinterizados de Argila Calcinada, Diss. Mestrado, Progr. Pós-Graduação em Eng. Civil, Universidade Federal do Amazonas (2011).

[16] C. S. Pinto, "Curso Básico de Mecânica dos Solos em 16 Aulas", Oficina de Textos, S. Paulo, SP (2000).

[17] M. R. V. Schwob, Perspectivas de difusão do gás natural na indústria Brasileira de cerâmica vermelha, Diss. Mestrado, Progr. Pós-Graduação de Engenharia da Universidade Federal do Rio de Janeiro, RJ (2007).

[18] M. Carvalho, Análise energo-exergética da indústria de cerâmica vermelha: estudo de caso cerâmica Santa Cecília Ltda, Diss. Mestrado, Progr. Pós-Graduação em Engenharia Mecânica, Universidade Federal da Paraíba, PB (2005).

[19] ANEEL, Resolução Homologatória 1.228 (25/10/2011), D.O. de 01.11.2011, seção 1, p. 63, v. 148, n. 210.

(Rec. 28/08/2012, Rev. 15/03/2013, Ac. 14/05/2013) 